\title{
Gangrena de Fournier en un niño con síndrome nefrótico corticorresistente. A propósito de un caso
} Fournier gangrene in a child with steroid-resistant nephrotic syndrome. Report of one case

\author{
Dra. María E. Padilla ${ }^{a}$, Dra. Sofía Fernández Berisso ${ }^{a}$, Dra. Agostina B. Vietri ${ }^{a}$ Dr. Lucas P. Trinitario ${ }^{a}$ \\ Dr. Miguel Liern ${ }^{b}$ Dra. Mirta S. Moreno ${ }^{c}$ y Dr. Miguel L. Podestád
}

\begin{abstract}
RESUMEN
La gangrena de Fournier es una fascitis necrotizante que afecta las regiones genital, perineal y perianal, de inicio súbito y diseminación rápidamente progresiva. Su diagnóstico obliga a una urgente intervención interdisciplinaria. La asociación con enfermedades nefrológicas es rara.

Se presenta un caso de gangrena de Fournier en un niño con síndrome nefrótico corticorresistente y anasarca con edema escrotal grave. Recibió un esquema antibiótico de amplio espectro y se realizó un desbridamiento quirúrgico extenso e inmediato de la lesión necrótica. Posteriormente, requirió reparación por parte de Cirugía Plástica. Presentó una respuesta clínica favorable a la terapéutica instaurada.

Palabras clave: síndrome nefrótico, gangrena de Fournier, fascitis.
\end{abstract}

\section{ABSTRACT}

Fournier gangrene is a necrotizing fasciitis that affects the genital, perineal and perianal regions, of sudden onset and rapidly progressive dissemination. Its diagnosis requires an urgent and interdisciplinary intervention. The association with nephrologic diseases is rare.

We present a case of Fournier gangrene in a child with steroidresistant nephrotic syndrome and anasarca with severe scrotal edema. He received a broad-spectrum antibiotic scheme and extensive an immediate surgical debridement of the necrotic lesion was carried out. Subsequently, it was repaired by Plastic Surgery. He presented a favourable clinical response.

Key words: nephrotic syndrome, Fournier gangrene, fasciitis.

http:/ / dx.doi.org/10.5546/ aap.2020.e204

Cómo citar: Padilla ME, Fernández Berisso S, Vietri AB, Trinitario LP, et al. Gangrena de Fournier en un niño con síndrome nefrótico corticorresistente. A propósito de un caso. Arch Argent Pediatr 2020; 118(2):e204-e207.

a. Clínica Pediátrica.

b. Servicio de Nefrología.

c. Servicio de Cirugía Plástica.

d. Servicio de Urología.

Hospital de Niños "Dr. Ricardo Gutiérrez",

Ciudad Autónoma de Buenos Aires, Argentina.

Correspondencia:

Dra. María E. Padilla: maemiliapadilla@gmail.com

Financiamiento: Ninguno.

Conflicto de intereses: Ninguno que declarar.

Recibido: 21-7-2019

Aceptado: 16-9-2019

\section{INTRODUCCIÓN}

La gangrena de Fournier es una fascitis necrotizante que afecta las regiones genital, perineal y perianal, de inicio súbito y diseminación rápidamente progresiva. ${ }^{1}$ Lleva el nombre del venereólogo francés Jean-Alfred Fournier, que, en el año 1883, definió este cuadro clínico a partir de cinco casos. ${ }^{2}$

Su diagnóstico obliga a una urgente intervención interdisciplinaria, que incluye la estabilización clínica del paciente, la antibioticoterapia adecuada, el desbridamiento y la exéresis de los tejidos necróticos, y la posterior reparación por parte de Cirugía Plástica. ${ }^{1}$

La mortalidad varía en las distintas series publicadas. En un estudio epidemiológico realizado en los Estados Unidos, que incluyó a 1680 pacientes, la mortalidad resultó del 7,5 \%,3 sustancialmente más baja que la hallada en series de casos de centros de atención terciaria. ${ }^{4}$ La asociación con enfermedades nefrológicas es rara. Se ha reportado un único caso de gangrena de Fournier en un niño con síndrome nefrótico idiopático. ${ }^{5}$

\section{CASO CLÍNICO}

Niño de 5 años de edad con síndrome nefrótico primario corticorresistente de 1 año de evolución, en tratamiento con meprednisona a razón de $10 \mathrm{mg}$ / día y micofenolato mofetil.

El paciente consultó por un síndrome febril de 12 horas de evolución y grave dolor escrotal que le impedía la deambulación. Se constató un niño en regular estado general, febril (temperatura de $38,2{ }^{\circ} \mathrm{C}$ ), taquicárdico y que, al momento del examen físico, presentaba anasarca con pene y escroto edematosos, eritematosos y dolorosos (Figura 1).

El análisis de laboratorio mostró leucocitosis con fórmula desviada a la izquierda (10 600/ $\mathrm{mm}^{3}$ de glóbulos blancos, el $6 \%$ de cayados, el $74 \%$ de neutrófilos segmentados, el $16 \%$ de linfocitos) con aumento de proteína $\mathrm{C}$ reactiva 
(PCR: $156 \mathrm{mg} / 1)$, hipoalbuminemia $(1,1 \mathrm{~g} / \mathrm{dl})$, urea $(27 \mathrm{mg} / \mathrm{dl})$ y creatinina $(0,3 \mathrm{mg} / \mathrm{dl})$ e hiponatremia (122 meq/1). El análisis de orina mostró proteinuria en rango nefrótico $(1611 \mathrm{mg} / \mathrm{l}$; relación proteinuria/creatininuria de 35,96 ).

El paciente se internó en la Unidad de Nefrología; inició el tratamiento con clindamicina (30 mg/ kg/día) y vancomicina $(60 \mathrm{mg} / \mathrm{kg} /$ día), y se colocó una sonda permanente por vía transuretral. Los hemocultivos realizados resultaron negativos. En las siguientes 48 horas, evolucionó con aumento de la hiperemia en el pene, el prepucio y el escroto, que se encontraban, a su vez, tumefactos y con áreas necróticas (Figura 2).

Ante el diagnóstico presuntivo de gangrena de Fournier, se procedió al desbridamiento amplio y a la resección completa de las lesiones penoescrotales bajo anestesia, por lo que quedó al descubierto el tallo peneano, testículos y cordones espermáticos (Figura 3). Se envió el tejido necrótico a cultivo y a anatomía patológica. A continuación, se rotó el esquema antibiótico a meropenem $(60 \mathrm{mg} / \mathrm{kg} /$ día $)$, clindamicina (30 mg/kg/ día) y amikacina $(7,5 \mathrm{mg} / \mathrm{kg} /$ día ) y se asoció con sesiones diarias con oxigenoterapia en cámara hiperbárica durante una semana.

FIGURA 1. Región genital en el momento del ingreso hospitalario: se observa edema y eritema

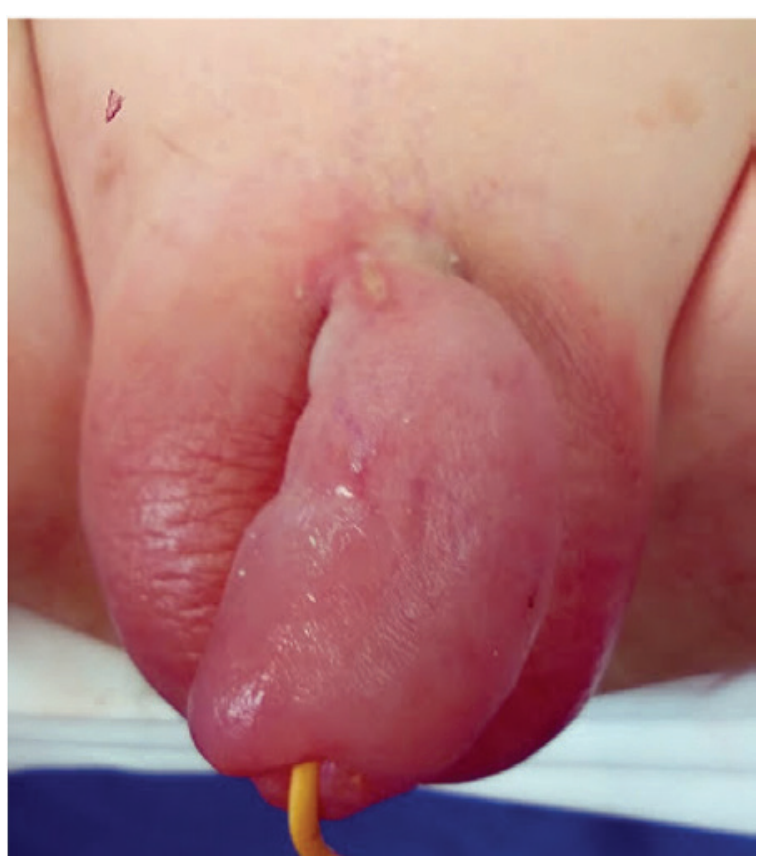

La anatomía patológica informó fascitis necrotizante. En el cultivo de los tejidos necróticos se aisló Serratia marcescens, ante lo cual se mantuvo el esquema antibiótico indicado previamente por tres semanas. Después, se inició profilaxis con trimetoprim-sulfametoxazol hasta 48 horas luego de la reconstrucción plástica de la lesión para evitar la sobreinfección bacteriana.

Paralelamente al tratamiento quirúrgico e infectológico, el paciente recibió, desde su ingreso, tratamiento con meprednisona ( $10 \mathrm{mg} /$ día) por su enfermedad de base, así como diuréticos y albúmina endovenosa por su cuadro de anasarca. Al día catorce de internación, se observó una mejoría del cuadro infectológico, pero no del síndrome nefrótico, y presentó proteinuria masiva $(5,3 \mathrm{~g} / 1)$, por lo que se inició el tratamiento inmunosupresor con ciclosporina. Además, se consideró que la anasarca era refractaria al tratamiento médico y se indicó la ultrafiltración lenta intermitente diaria por dos semanas. Para garantizar un aporte calórico adecuado, recibió alimentación enteral por sonda nasogástrica con fórmula hidrolizada. Surgió como complicación del sondaje vesical permanente y del tratamiento antibiótico una infección urinaria secundaria a Candida albicans, por lo que recibió desoxicolato de anfotericina $B$ por tres semanas.

FIgURA 2. Lesión a las $48 \mathrm{~h}$ del ingreso: aumento de la hiperemia y zonas de necrosis

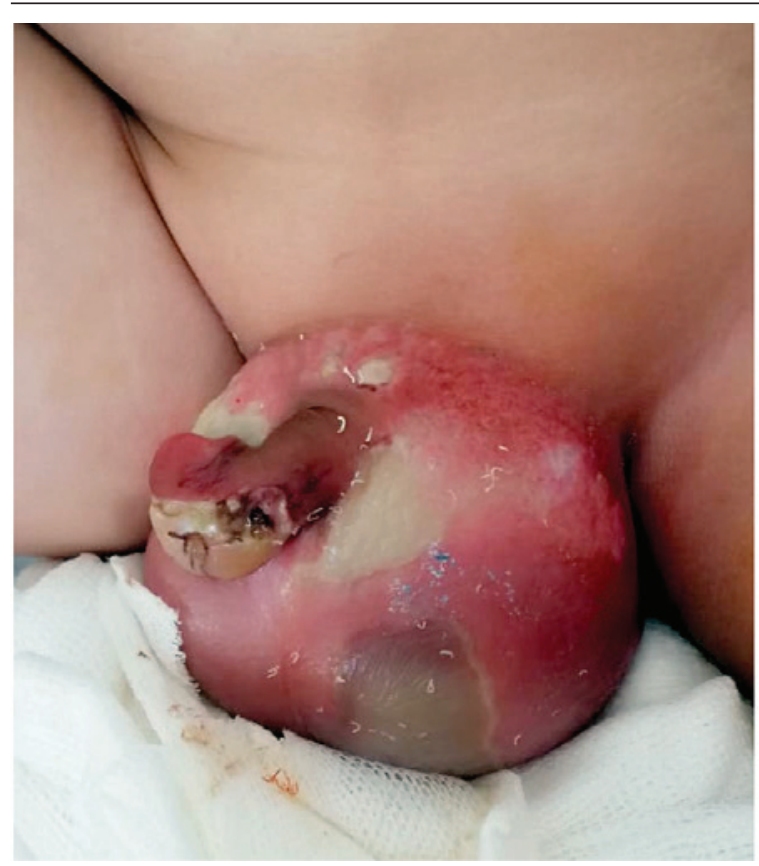


En el aspecto quirúrgico, a partir del desbridamiento, se realizaron curaciones locales bajo anestesia general con colagenasa. A las 4 semanas, conjuntamente con el Servicio de Cirugía Plástica, se inició la reconstrucción genital con la liberación de la base peneana y la colocación de matriz dérmica acelular bicapa en la región peneana y escrotal para la preparación de un lecho adecuado que permitiera la recepción del injerto de piel. A las dos semanas, se retiró la capa siliconada y se colocó el injerto de piel parcial tomado con dermatomo eléctrico del muslo derecho, que cubrió completamente la zona genital comprometida. La zona dadora se trató con curación oclusiva con un parche de hidrocoloide.

En el control a los 7 días, se observó el prendimiento al $100 \%$ del injerto y la epitelización progresiva de la zona dadora. A los 15 días, se comprobó la epitelización completa del injerto y de la zona dadora. El paciente presentó buena evolución clínica. Egresó luego de ocho semanas de internación (Figura 4), sin presentar signos de infección; se encontraba en remisión el síndrome nefrótico, con albúmina sérica de $3,6 \mathrm{~g} / \mathrm{dl}$ y la función renal dentro de los límites normales. En los controles alejados después de 2 meses, se observó buena elasticidad de la piel peneana, sin adherencias ni retracciones.

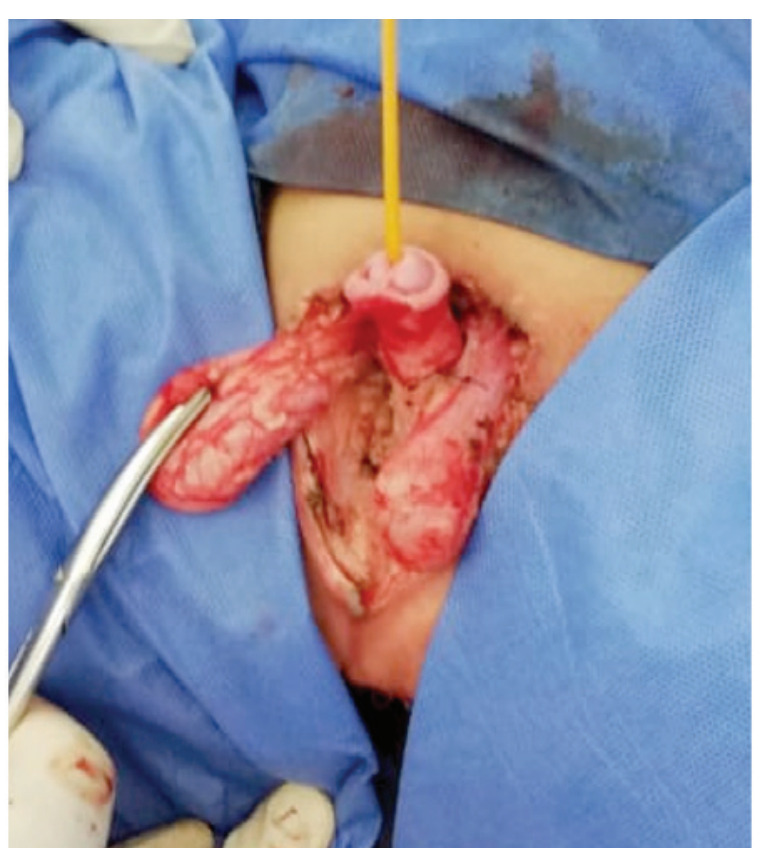

\section{DISCUSIÓN}

La gangrena o enfermedad de Fournier es una infección necrotizante de la región genital descrita por primera vez en 1764 por Baurienne. ${ }^{6}$ Afecta a hombres y mujeres, con franco predominio en el sexo masculino, y su frecuencia es baja en pediatría. $^{7}$

La enfermedad comienza con una infección del tejido celular subcutáneo por bacterias productoras de toxinas, las cuales generan una lesión tisular que afecta a todas las capas de la piel hasta producir una fascitis. Posteriormente, se desarrolla una endoarteritis obliterante, responsable de la trombosis vascular y de la necrosis tisular consecuente. ${ }^{8}$

Con respecto a los agentes causales, se trata de una infección polimicrobiana en un 50-80 \% de los casos, según las series analizadas. ${ }^{7,9}$ Escherichia coli es el germen hallado con mayor frecuencia. Otros patógenos incluyen Streptococcus, Bacteroides, Enterobacter, Staphylococcus, Enterococcus, Pseudomonas, Corynebacterium, Klebsiella pneumoniae y Candida albicans. ${ }^{7,9}$

En los últimos años, se han reportado casos originados por gérmenes resistentes, tales como Staphylococcus aureus meticilino resistente o E. coli productora de betalactamasas. ${ }^{10} \mathrm{En}$ el caso del paciente descrito, se aisló S. marcescens en el cultivo del tejido necrótico, pero se

FIGURA 4. Región gential en el momento del egreso hospitalario

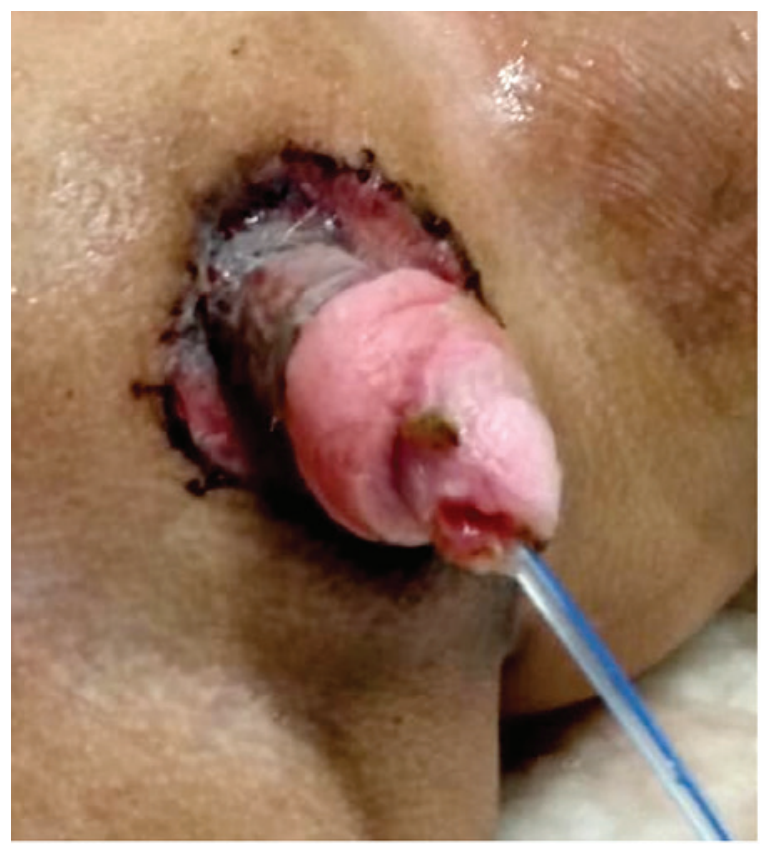


decidió mantener el esquema antibiótico de amplio espectro debido a la elevada frecuencia de infección polimicrobiana reportada en la literatura.

En pediatría, se han publicado casos en pacientes con enfermedades oncohematológicas, aunque, con mayor frecuencia, sucede en niños previamente sanos con una comorbilidad aguda predisponente: cirugía genitourinaria, trauma (parafimosis), infecciones dérmicas locales (varicela, infecciones perianorrectales) o patología estructural urológica (extravasación periuretral de orina). ${ }^{11}$ La puerta de entrada de la infección suele ser cutánea, urogenital o anorrectal. ${ }^{8}$

Se puede considerar al paciente descrito inmunosuprimido por presentar síndrome nefrótico con proteinuria masiva y por encontrarse en tratamiento inmunosupresor. ${ }^{12}$ La puerta de entrada de la infección puede haber ocurrido por una lesión en la región genital edematizada.

El diagnóstico de gangrena de Fournier es, principalmente, clínico. Los hallazgos en el examen físico incluyen fiebre, eritema y edema perineal, entumecimiento local y dolor grave. ${ }^{1}$ En general, los testículos no se encuentran comprometidos debido a su irrigación arterial independiente de la penoescrotal. ${ }^{8}$ Los exámenes de laboratorio y estudios por imágenes contribuyen a evaluar la extensión de la lesión y el compromiso multisistémico, pero su realización no debe nunca demorar el inicio del tratamiento de forma innecesaria. ${ }^{1}$

Con respecto a la terapéutica, considerando el cuadro rápidamente evolutivo, debe ser instaurada de manera urgente. Se basa en dos pilares fundamentales: el tratamiento antibiótico agresivo y empírico al comienzo (con cobertura para Gram-positivos, bacilos Gram-negativos y anaerobios) y el desbridamiento quirúrgico amplio e inmediato de la lesión necrótica. ${ }^{8} \mathrm{La}$ terapia con oxígeno hiperbárico se recomienda como adyuvante de la cirugía y actuaría favoreciendo la función fagocitaria e interfiriendo en el crecimiento de bacterias anaerobias. ${ }^{13}$ No obstante, los trabajos que evalúan su efectividad en pediatría son escasos y limitados. ${ }^{14}$
Finalmente, se debe remarcar la importancia de un adecuado aporte nutricional considerando la extensa pérdida de tejido y el cuadro infeccioso, que provocan un aumento de la tasa del metabolismo basal. ${ }^{15}$ En este caso, frente al cuadro clínico grave, de rápida evolución y elevada morbimortalidad, la decisión inmediata de desbridar quirúrgicamente la lesión necrótica, junto con la terapéutica antibiótica de amplio espectro, el uso de cámara hiperbárica y la administración de un aporte nutricional, constituyeron medidas terapéuticas adecuadas que revirtieron la progresión de esta patología gangrenosa.

\section{REFERENCIAS}

1. Voelzke BB, Hagedorn JC. Presentation and Diagnosis of Fournier Gangrene. Urology. 2018; 114:8-13.

2. Fournier JA. Gangrène foudroyante de la verge. Sem Méd. 1883; 3(56):345-7.

3. Sorensen MD, Krieger JN. Fournier's Gangrene: Epidemiology and Outcomes in the General USP Population. Urol Int. 2016; 97(3):249-59.

4. BarupalSR, Soni ML, Barupal R. Factors Affecting Mortality Following Necrotizing Soft-Tissue Infections: Randomized Prospective Study. J Emerg Trauma Shock. 2019; 12(2):108-16.

5. Wright AJ, Lall A, Gransden WR, Joyce MR, et al. A case of Fournier gangrene complicating idiopathic nephrotic syndrome of childhood. Pediatr Nephrol. 1999; 13(9):838-9.

6. Baurienne H. Sur une plaie contuse qui s'est terminee par le sphacele de la scrotum. J Med Chir Pharm. 1764; 20:251-6.

7. Tang LM, Su YJ, Lai YC. The evaluation of microbiology and prognosis of Fournier's gangrene in past five years. Springerplus. 2015; 4:14.

8. Hagedorn JC, Wessells H. A contemporary update on Fournier's gangrene. Nat Rev Urol. 2017; 14(4):205-14.

9. Aridogan IA, Izol V, AbatD, KarsliO, et al. Epidemiological characteristics of Fournier's gangrene: a report of 71 patients. Urol Int. 2012; 89(4):457-61.

10. Lin WT, Chao CM, Lin HL, Hung MC, et al. Emergence of antibiotic-resistant bacteria in patients with Fournier gangrene. Surg Infect (Larchmt). 2015; 16(2):165-8.

11. Cundy TP, Boucaut HAP, Kirby CP. Fournier's gangrene in a child with congenital genitourinary anomalies. J Pediatr Surg. 2012; 47(4):808-11.

12. Moorani KN, Khan KM, Ramzan A. Infections in children with nephrotic syndrome. J Coll Physicians Surg Pak. 2003; 13(6):337-9.

13. Gandhi J, Seyam O, Smith NL, Joshi G, et al. Clinical utility of hyperbaric oxygen therapy in genitourinary medicine. Med Gas Res. 2018; 8(1):29-33.

14. LiC, ZhouX, Liu LF, Qi F, etal.Hyperbaric Oxygen Therapy as an Adjuvant Therapy for Comprehensive Treatment of Fournier's Gangrene. Urol Int. 2015; 94(4):453-8.

15. Rodríguez Alonso A, Pérez García MD, Núñez López A, Ojea Calvo A, et al. Gangrena de Fournier: aspectos anátomo-clínicos en el adulto y en el niño. Actualización terapéutica. Actas Urol Esp. 2000; 24(4):294-306. 